\title{
Formación (Bildung) y creación literaria "Llegar a ser lo que se es" en diversos mundos posibles*
}

Fecha de recepción: 10 de junio de 2017

Fecha de aprobación: 12 de septiembre de 2017

\section{Resumen}

La invención de mundos posibles que supone la creación literaria posibilita nuevas formas de existencia desde la ficción. Para la pedagogía de la literatura esto implica profundizar en la idea de formación (Bildung) como autorrealización espiritual de las personas al trascender su realidad inmediata y desbordar los sentidos educativos propuestos, transitando lugares desconocidos que anidan en su interior, como cultivo personal. Por esta razón, este artículo derivado de investigación doctoral relaciona estos dos conceptos - Bildung y creación literaria - desde su dimensión estética, en tanto construcciones significativas de nuevas formas de ser y de vivir, hasta proponer una formación literaria basada en la escritura de ficción como despliegue interior para explorar la condición humana, en respuesta a la marginalidad de este tipo de producciones en el sistema educativo.

Palabras clave: Formación, Bildung, Pedagogía de la literatura, Formación literaria, Estética, Creación literaria, Ficción.

Citar: Saavedra Rey, S. (julio-diciembre 2017). Formación (Bildung) y creación literaria. "Llegar a ser lo que se es" en diversos mundos posibles. La Palabra, (31), 197-210. doi: https://doi.org/10.19053/01218530.n31.2017.7267.

\section{Sneider Saavedra Rey}

Docente e investigador de la Universidad de San Buenaventura, vinculado al grupo Tendencias Actuales en Educación y Pedagogía (TAEPE). Magíster en Educación y Licenciado en Humanidades, Español y lenguas extranjeras, de la Universidad Pedagógica Nacional. Candidato a Doctor en Humanidades, Humanismo y persona, de la Universidad de San Buenaventura.

sneider201@hotmail.com

* Artículo de investigación derivado del proyecto investigativo "La creación literaria como dispositivo estético para la formación humana". 


\section{la palabra}

\section{Education (Bildung) and Creative Writing "Becoming What One Is" in Diverse Possible Worlds}

\section{Abstract}

The invention of possible worlds implied by literary criticism enables new forms of existence motivated by fiction. For a pedagogy of literature, it is necessary to reflect about the idea of education (Bildung) as spiritual self-realization where persons transcend their immediate reality and surpass the proposed educational meanings, discovering and travelling through unknown places inside themselves, in a process of personal growth. This article is derived from doctoral research that relates these two concepts - Bildung and creative writing - from their aesthetic dimension, as significant constructions of new ways of living and being, until developing a proposal of literary education based on fiction writing as an inner unfolding that allows for the exploration of the human condition, contrary to the marginality of this type of work in the educational system.

Keywords: education, Bildung, pedagogy of literature, literary education, aesthetics, creative writing, fiction.

\section{Formation (Bildung) et création littéraire: "parvenir à être ce que l'on est", dans plusieurs mondes possibles}

\section{Resumé}

l'invention de mondes possibles dans la création littéraire permet de nouvelles formes de l'existence dans la fiction. Ceci nous permet de réfléchir, en tant que pédagogues de la littérature, á l'idée d'une formation (Bildung) comme épanouissement spirituel personnel au moment où la réalité immédiate ainsi que les significations traditionnelles de l'éducation sont dépassées. Ainsi, des espaces inconnus qui se trouvent à l'intérieur de chacun apparaitraient comme une manière de se cultiver à soi-même. Cet article, qui est le produit d'une recherche doctorale, met en rapport deux concepts- Bildung et création littéraire -à partir de sa dimension esthétique, en tant que constructions de nouvelles formes d'être et de vivre. Nous proposons une formation littéraire à partir de l'écriture de fiction comme un déploiement de l'intériorité qui permettrait d'explorer la condition humaine, en réponse au caractère marginal de ce type de productions dans le système éducatif.

Mots-clés: formation, Bildung, pédagogie de la littérature, formation littéraire, esthétique, création littéraire, fiction. 
"Nuestra verdad posible tiene que ser invención, es decir escritura, literatura..." Julio Cortázar, Rayuela

\section{Introducción}

Desde la idea de Bildung desarrollada en la tradición pedagógica alemana, la formación refiere al cultivo personal para alcanzar la plenitud humana, reconociendo la existencia singular como una obra en construcción, que se resume en la sentencia de Píndaro «llega a ser lo eres». Esta concepción estética, como búsqueda constante que trasciende la realidad inmediata de la persona, llevándola a lugares intransitados que anidan en su interior, le permite desbordar lo propuesto, interpretar lo que le es enseñado, dar sentido a la propia existencia, transformarla, encontrar otras maneras de ser y de vivir, como proceso espiritual de autorrealización, que incluso puede trasgredir las orientaciones externas de la educación al respecto.

En este sentido, la creación literaria, a pesar de su marginalidad en las prácticas educativas referidas al lenguaje, la lengua y la literatura, podría participar de dicho proceso formativo, pues la ficción, sus estrategias y elementos discursivos, supone una creación de lo no conocido, una invención, que expresa la necesidad humana «de lo imaginario, además de lo acaecido y real» (Marías, 1995). Escribir con intencionalidades estéticas para realizar algo que pueda ser considerado literatura, es crear mundos posibles en tanto nuevas alternativas de existencia; significa experimentar, en el proceso creativo, otras dimensiones de la «realidad real», la cual puede resultar más vívida, enriquecida, una vez es narrada o poetizada, pues el primer contacto con los acontecimientos siempre es limitado en sus contingencias. Incluso, cuando refiere a tal realidad en formas biográficas o cercanas al discurso histórico, sus recursos retóricos «ficcionalizan» sus hechos, ampliando sus posibilidades de existencia (Arias et al., 2013).

Si la formación es una indagación de uno mismo, no desde lo que se es, sino desde lo que se podría llegar a ser, la creación de mundos de ficción, alternos al real, a partir del único material que posee quien escribe, su propia existencia; configura un viaje interior para buscar en uno mismo lo que hasta ahora no ha sido, pues «lo estético se orienta a escudriñar el mundo dentro de un marco de potencias y contingencias, creando una virtualidad analógica» (Cárdenas, 2009, p. 12). Es aquí donde el planteamiento clásico de la Poética aristotélica según el cual «la poesía es más filosófica y más doctrinal que la historia» retoma valor, pues evidente- mente la segunda «cuenta las cosas tales como sucedieron» mientras la primera «como debieran o pudieran haber sucedido» (Aristóteles, 2007, p. 28). Es en ese despliegue de posibilidades donde la poesía - «único medio humano [...] que daría la armonía entre nuestro ser y todo lo que éste no es» (Béguin, 1997, p. 9)- evidencia su carácter formativo para quienes la leen y escriben.

Este artículo, entonces, aborda la formación -así como su distinción y relaciones con la educación- reconociéndola como proceso imbricado en la existencia humana cuya consolidación conceptual es producto de la modernidad en una nación específica, mediante la Bildung. Ya en el ámbito de la pedagogía de la literatura, plantea la condición marginal de la creación literaria en el contexto educativo y las posibilidades de un nuevo campo, el de la formación literaria, basado en la escritura creativa, para configurar desde la ficción otras posibilidades del ser del hombre, en su trasegar por otros mundos posibles.

\section{La formación (Bildung), más acá de la acción educativa}

Debido a que se desarrolla en el seno de una lengua, una cultura y una tradición pedagógica específica, la distinción entre Bildung (formación) y Erziehung (educación), planteada desde la obra pedagógica de Herbart, 
ha suscitado múltiples estudios de base etimológica y filosófica aún en los últimos años (Garcés y Runge, 2011; Horlacher, 2004; Fabre, 2011; Ipland, 1999). En tales aproximaciones, el primer concepto es abordado como rasgo humano de autorrealización del sujeto, para su transformación desde adentro, debido a que forja la libertad desde la razón, la sensibilidad y la voluntad, en la interrelación con otros y sus contextos socioculturales específicos. Así como la educación atañe a un medio de instrucción o adiestramiento en ciertos conocimientos $\mathrm{y}$ habilidades -una acción externa, pedagógicamente intencionada-, la formación permite «alcanzar la plenitud humana» (Kant, 2008), «llegar a ser persona» (Quintana, 1986), y «llegar a ser lo que se es» (Nietzsche, 2002), en tanto devenir espiritual.

Si bien la Bildung se configura en el debate educativo del siglo XVIII, se ha evidenciado su devenir desde el misticismo de la Edad Media porque supone «reconstruir en cada persona la imagen de lo divino que lleva en sí» (Aranguren, 2004, p. 36); su cultivo personal. También sus conexiones con la paideia griega (Vilanou, 2001), pues el marco de la filosofía antigua como modo de vida implicó una articulación de la cultura y la educación como parte de «la estructura histórica objetiva de la vida espiritual de una nación» (Jaeger, 2001, p. 2). Es más, estos estudios han concluido que la formación es un concepto íntimamente vinculado a la evolución humana en toda su historia, desde «los protoorígenes del hombre», pues «la necesidad formativa proviene de una lógica interna, de una dialéctica del concepto con la existencia humana» (Ipland, 1999, p. 49).

Sin embargo, el sentido moderno con el que se difunde este concepto solo se desarrolla en Alemania vinculado al pietismo, que relaciona la apariencia exterior con el interior humano (su alma), pues desde la auto-observación y la au- toreflexión personal se busca la comprensión del mundo y de la naturaleza. Dicho énfasis en la autoformación se vinculó al desarrollo de un estilo o manera de vivir (una estética), que cada persona proyecta ante sí misma para realizarse dentro de sus múltiples posibilidades de existencia. Así pues, este concepto «se centra principalmente en los procesos internos y no puede describirse como educación en el sentido de crianza o capacitación. Bildung tampoco es conocimiento; en cambio, describe una autocomprensión estética con una pretensión de verdad y bondad» (Horlacher, 2004, p. 38).

Aunque es notorio en el campo conceptual que «estamos asistiendo a una actualización del tema de la Bildung» (Vilanou,
2001), e incluso en algunos países europeos este concepto ha posibilitado la lucha política frente a la racionalidad técnica de ciertos discursos educativos (Horlacher, 2004); esta distinción fundamental entre educar (desde el exterior) y formarse (interiormente) no se ha desarrollado con suficiencia en el contexto colombiano, cuyas orientaciones curriculares y acciones del profesorado se limitan a directrices educativas cuyos resultados tangibles esperan medirse en ciertas pruebas estandarizadas. Tanto así, que el mismo discurso de la calidad, las competencias y la capacitación laboral, plantea «lo formativo» como parte de sus derroteros, circunscribiendo el sentido de la formación solo a uno de sus aspectos, su carácter «procesual», en el marco de prácticas administrativas $\mathrm{y}$ empresariales, referidas al control, el seguimiento y la regulación; supeditadas a resultados predecibles $\mathrm{y}$ medibles.

Pero la formación como proceso interior, espiritual y volitivo, supera estos condicionamientos, haciéndose creativa y contingente, en tanto estética proyectada por cada persona para desplegar una manera singular de concebirse, de ser y de vivir. Así, no refiere a un producto de la educación, pues «lo que cada quien porta y comporta son efectos de formación», por lo cual «no se 
puede esperar "producción en serie", repetición de lo mismo bajo cánones de la producción industrial [...] la formación brota de cada quien al reaccionar (desbordar) lo propuesto» (Vargas Guillén, 2010, p. 37). En otras palabras, el acto de formar (interno) desborda la acción educativa (externa), de la cual no se puede prescindir, pues vincula culturalmente a la persona y la encara en el ámbito social, problematizando su interior. «Así, entonces, la formación no es proyecto, sino sentido destinal. No es una verdad que se tenga que repetir, una y otra vez; sino una interpretación que debe ser revisada, refundada, reinstaurada en el desbordamiento» (p. 36). Quien se forma reconoce la importancia de lo que estudia porque lo internaliza o, más precisamente, porque le despierta un estímulo interior al que está llamado a seguir. Quien solo aprende lo previsto de la acción educativa, sin ponerse en cuestión, conoce de teorías, estrategias, técnicas y procedimientos, pero esto no garantiza que tales saberes lo constituyan como persona, que hagan parte de su espíritu y formación vital.

Quizá, las mejores ilustraciones para comprender esta distinción entre educar y formar sean las aproximaciones que desde la ficción y el mito ha realizado Merieu (2007) para exponer el problema de la educación como fabricación. Desde personajes como Pigmalión, Pinocho, el Golem y, por supuesto, Frankestein, este autor cuestiona la ambición educativa de controlar el destino del hombre: «ise puede 'formar', sin 'fabricarlo', un ser que se nos asemeje, que nos lo deba todo, y que al mismo tiempo, no esté obligado a nada respecto a nosotros? [...] ¿se puede renunciar a 'hacer al otro' sin renunciar a educarlo?» (Merieu, 2007, p. 49). Enfocándose en el último personaje que da título a su obra, Frankestein educador, y retomando la distinción entre poiesis como fabricación que se detiene cuando alcanza su objetivo y praxis como acción que no tiene finalidad en sí misma, analiza que la educación no puede quedarse en el «amaestramiento» para hacer del hombre lo que la sociedad previamente ha definido como su propósito de realización, pues él construye el sentido de su existencia, siempre imprevisible. De ahí que, una de sus conclusiones sea la fatalidad de un proyecto educativo que no contemple tales contingencias, ya que obra con humanos, con agentes espirituales, físicos, mentales $\mathrm{y}$ volitivos; no con objetos: «lo normal, en educación, es que la cosa no funcione: que el otro se resista, se esconda o se rebele [...], a veces, simplemente, para recordarnos que no es un objeto en construcción sino un sujeto que se construye» (p. 73).

Así pues, la formación refiere a ese «ser obra de sí mismo» que
Merieu (2007) retoma de Pestalozzi, para lo cual la educación moviliza todo lo necesario para que «el sujeto entre en el mundo y se sostenga en él, se apropie de los interrogantes que han constituido la cultura humana, incorpore los saberes elaborados por los hombres en respuesta a esos interrogantes... y los subvierta con respuestas propias» (p. 70). Como se advierte, la educación posibilita una experiencia profunda en el escenario cultural y social al cual el niño llega al nacer, desde su contexto familiar hasta la escuela, atravesando todos los ámbitos externos que procuran acogerlo y legarle una visión de mundo y un modo de vida; mientras la formación es su desbordamiento interior, el despliegue de sus posibilidades, que evidencia una respuesta propia -conciencia, voluntad, toma de postura, autonomía- y que, en cuanto tal, trasciende lo propuesto por aquellas acciones educativas. Formación como trabajo sobre sí mismo para forjar el hombre al que se aspira, ese que solo se es en potencia, contenido en uno mismo como deseo y posibilidad, pero que debe desplegarse, desbordarse, convertirse, trans-formarse.

Formación como desbordamiento de sentidos: implicaciones pedagógicas

En La humanización como formación. La filosofía y la enseñanza de la filosofía en la condición postmoderna, Vargas 
Guillén (2010) plantea una actualización de esta idea de formación desde la fenomenología y la antropología pedagógica. Con este propósito, parte de la definición de Heidegger, quien afirma que formar es «poner en libertad el ser en la comparecencia del ente mismo», lo cual es ampliado por el autor en los siguientes términos:

Se trata de que el ser alcance la plenitud de su despliegue mediante su propia exposición por vía de, a través de y en el lenguaje. En esta perspectiva la formación no puede ser una estrategia de imposición, de instrucción, de modelamiento, sino en la medida que el ser se expone propicia un salto, un paso fuera de sí. (Vargas Guillén, 2010, p. 9).

Desde esta perspectiva, la formación no refiere a un proyecto sino a un «sentido destinal»; no es una verdad que debe ser repetida sino una interpretación constante del sujeto que no es producto directo de la instrucción, solo su efecto. Es un acto de desbordamiento del ser por medio del lenguaje, que es el único medio en el cual puede ex-poner (expresar) sus posibilidades de existencia.

Por esta razón, este filósofo plantea la escritura como una construcción de sentido que posibilita el despliegue del ser, siendo registro individual de un hombre sobre el mundo (construcción de un sentido vivido) para que otros y él mismo lo interpreten, amplíen o desborden. No en vano diversos autores -Paz (2005), Bruner (2004), Manguel (2010), Larrosa (1998), Heidegger (2013), Gadamer (2012), Béguin (1997)consideran el lenguaje como condición de la existencia del hombre, ya que solo mediante este entramado simbólico configura su ser, sus proyecciones como sujeto y, en comunidad, su cultura.

En este marco, la pedagogía como proyecto de formación es «un problema filosófico del sentido con el que los seres humanos dan contenido a sus horizontes de ser, en la construcción de sus proyectos individuales y colectivos» (p. 59). Por tanto, busca desplazar los discursos objetivos sobre los sujetos, para que ellos mismos se narren, enriqueciendo sus visiones de mundo desde la necesidad $-\mathrm{y}$ complejidad-de relacionarse y a la vez de diferenciarse; de ser uno mismo mediado por el otro. Esto precisa de «un ambiente para que el sujeto se forme, para que se despliegue y se construya a sí mismo en la interacción» (p. 109), generando sentidos desde una experiencia significativa, interior, transformadora, que «configura una personalidad, un carácter, una sensibilidad, o en definitiva, una forma humana singular que es a su vez una ética (un modo de conducirse) y una estética (un estilo)» (Larrosa, 2013, p. 34). La pedagogía renueva tal construcción personal para que cada quien quede interpretado desde su implicación en la comunidad y realice su despliegue estético. En clave fenomenológica, solo de esta manera el ser-ahí, arrojado a la existencia, proyecta sus potencias en el ámbito social y cultural, se desborda, constituyéndose en ser-en-el-mundo desde la experiencia, resignificando así el espacio que habita como mundo de la vida.

Para la pedagogía de la literatura en particular, esto implica enfatizar en la significación (construcción de sentido) en los procesos de lectura y escritura del texto literario, lo cual parecería una obviedad para cualquier proceso de semiosis, de acuerdo con los propósitos comunicativos de cada texto. Sin embargo, el tratamiento extraliterario que el sistema educativo impone a la literatura ha obnubilado sus intencionalidades estéticas entre un cúmulo de datos historiográficos, culturales, ideológicos o teóricos, los cuales han extraviado las relaciones texto-lector y autor-texto hacia "discursos paraliterarios" (Bombini, 1996), que abarcan desde las prácticas normativistas de la antigua retórica o el enciclopedismo, hasta los análisis estructuralistas y sociológicos más recientes, y que no permiten experimentar las alter- 
nativas vitales que configura la ficción. De ahí que, difícilmente estas obras se impliquen en la vida personal de sus participantes, desde las singularidades y los universales que a aquellas como a ellos les conciernen para explorar la condición humana. Esto dificulta la proyección formativa de lectores cautivos en objetivos informativos, y de escritores potenciales que no encuentran lugar en las prioridades curriculares para el despliegue personal de sentidos desde la página en blanco; desde la creación.

La creación literaria, en los márgenes del sistema educativo

Al menos discursivamente, la lectura literaria ha ganado un lugar en la escuela como experiencia formativa, de acuerdo con propuestas de autores como Rosenblatt (2002), Larrosa (2013), Nussbaum (2012; 1995), Todorov (2009), Mélich (2003; 2014) y Bárcena (2012; 2014), entre otros. Leer literatura «como algo que nos forma (o nos de-forma o nos transforma), como algo que nos constituye o nos pone en cuestión en aquello que somos» (Larrosa, 2013, p. 26), es una consigna que repiten maestros progresistas y políticas educativas recientes, más allá de las contradicciones de sus prácticas. Desde el desarrollo de la estética de la recepción, en manos de autores como Iser, Jauss, Riffaterre, Gadamer, Fish o Warning, se ha concebido que el texto solo puede actualizarse mediante el acto de leer, en su encuentro con un lector y sus horizontes de sentido, configurando una experiencia: "lo literario del texto vive cuando el lector asume, revela, ausculta, critica, interpreta, y coexiste con la historia, sintiendo una des-acomodación, que lo invita a la reflexión de muchos temas, al encuentro consigo mismo y a alcanzar el goce del texto" (Bolívar y Gordo, 2016, p. 203).

La escritura, por su parte, está muy lejos de correr esta misma suerte, ni siquiera abordada con suficiencia en la normatividad $o$ en el discurso pedagógico. Si bien no se niega, su carácter formativo no se divulga y, menos aún, se concede un tiempo sistemático para abordar la creación en el aula. En una investigación reciente (Saavedra, 2011; 2013) se evidenció el estado marginal de la creación, la cual, de realizarse, es tomada simplemente como un apéndice de la lectura de obras (metodología del comentario de texto), medio de reproducción de saberes disciplinares (incluyendo elementos normativos de la lengua) o actividad complementaria que solo pretende «entretener» al estudiantado en algún momento libre de la clase. De este modo, las instituciones educativas han sido vicarias de la sustitución del concepto clásico de «poesía», derivado del verbo griego poein, que refiere a «hacer» enfatizando en las realizaciones verbales de carácter estético, por lo que, desde el siglo XVIII se conoce como «literatura» (del latín littera, «letra del alfabeto»), que evolucionó para referir lo «capaz de leer y ser leído» de acuerdo con una naciente sociedad alfabetizada (Llovet, 2012). Tanto así, que hoy la saturación informativa atraviesa tales procesos de recepción exigidos en las aulas, adelantándose a las posibilidades del efecto estético y cambiando la creación auténtica por re-producción de temas, formas, interpretaciones y motivos aceptados escolarmente.

Ya en 1991, Colomer planteaba el paso de la enseñanza de la literatura a la educación literaria como una transición significativa que privilegiaba el contacto con múltiples obras y su integración con diversos usos linguiísticos y textuales, complejizando la comprensión del hecho literario y sus relaciones sociales y culturales de manera dinámica. No obstante, en esa misma década, Eco (1994) advertía la perplejidad que generaban las propuestas estructuradas de enseñanza de la escritura, porque su abordaje en la academia carecía de tiempo y escasamente se estimulaban ejercicios tema-ensayo en los que se motivaba a los jóvenes a «ejercer de críticos literarios pero muy raramente a redactar escritos creativos propios» (Eco, 1994, p. 5). Esto pervive en los cen- 
tros escolares en general, que adolecen de «vertebración en el currículum escolar» de estos procesos de creación (Colomer, 1991), fundamentalmente porque el objetivo de la educación literaria no es la formación específica en este campo, sino su contribución a los procesos de alfabetización de las propuestas curriculares de Estado.

Si el carácter artístico de la literatura es un componente irrelevante en la enseñanza del lenguaje y la lengua, es consecuente que la creación literaria -su ámbito menos predecible, más subjetivo, inventivo y contingente- sea marginada de los programas académicos, de no ser como otra actividad de esparcimiento o un medio para el uso normativo de la lengua (Saavedra, 2011), dejando pendiente la cuestión de escribir en el aula (Delmiro Coto, 1995). La creación como laboratorio del lenguaje y de indagación por la existencia humana no se desarrolla en prácticas escolares que dejan asomar las páginas de la literatura con el fin de ejercitar la producción y la comprensión textuales como destrezas hacia la normatividad lingüística (especialmente, la adquisición de léxico, la cohesión sintáctica y la ortografía), o cuando ya se tiene una interpretación anticipada de género, corriente artística, período histórico e importancia para la humanidad, sin pensar en el valor de una página escrita por una persona para su formación, como indagación de su propia existencia, tal como lo han evidenciado Bruner (2004) y Ricoeur (1995).

Sin duda, esta es una problemática que atañe a la formación literaria, pues, aunque la lectura significativa posibilita construcciones de sentido cuestionando lo que cada lector es, se limita a las coordenadas de un texto forjado por otro, cuyos intertextos y contextos proveídos por el profesor u otras fuentes, aunque enriquecedores, pueden objetivar lo que debería ser experiencia subjetiva, tal y como se ha evidenciado en la realidad escolar; mientras que la escritura auténtica ofrece posibilidades ilimitadas para presentar otro mundo posible, en cuyo desarrollo hay mayores opciones de desbordar los sentidos desde el despliegue personal y de conocer desde adentro, en su uso, gramáticas y estrategias de creación. De hecho, esta vía creativa, basada en las funciones expresiva y estética del lenguaje, se presenta como un camino más propicio para comprender que la literatura es «una forma -quizá la más completa y profunda- de examinar la condición humana» (Sábato, 2014, p. 11) y un «escenario simbólico del mundo que posibilita una versión de lo real» (Ferrer, 2002, p. 16), pues implica una mirada introspectiva sobre la propia existencia y lo que esta no ha sido (o podría ser), en las interrelaciones de logros, decepciones, anhelos, frustraciones, sueños, miedos, etc., articulándose a la autorrealización personal. Esto genera nuevas perspectivas para la didáctica de la literatura, ya no desde el exterior (educativo) del texto, sino desde su interior (formativo), en el rigor de las decisiones que debe tomar el autor para organizar el mundo desde la invención.

\section{Hacia una formación literaria} basada en la escritura de ficción

¿Por qué prestar atención a estos procesos formativos desde la creación literaria? ¿Pueden estas ficciones servir a sus autores en su autorrealización interior? En primer lugar, estas creaciones, al igual que la Bildung, problematizan la predictibilidad educativa en busca de un uso no convencional de la lengua y de innovaciones formales, textuales y estilísticas, que configuran un mundo posible divergente, explorando la existencia de los seres humanos. De acuerdo con Cárdenas (2004), los elementos poesía, arte, lenguaje y mundo, constituyen la literatura, promoviendo «un ejercicio creativo y lúdico de la sensibilidad, la imaginación y el intelecto» que confiere «una manera de sentir, imaginar y conocer el mundo, con el fin de darle forma estética, poner en obra lo que antes no existía en la realidad y representarlo de manera sugerente» (Cárdenas, 
2004, p. 18). Esta concepción de lo poético como estética implica precisamente construir un mundo, el cual no puede salir de un lugar distinto al de la experiencia vital de quien escribe, como posibilidad de formación personal, indagando su propia existencia.

Desde el contexto local y reciente entre maestros, esta es la experiencia de Espitia (2013) cuya investigación asume la escritura no solo como «una forma diferente de ver las cosas y una crítica profunda a la sociedad», sino en términos de «invención arbitraria y constante de palabras» $\mathrm{y}$ «búsqueda de otras formas de decir», en tanto «necesidad de desbordamiento de los límites, de tergiversación del sentido». O dentro de la alta literatura, junto a infinidad de escritores que han reflexionado sobre su oficio, las palabras de Rivera-Garza (2010) sobre la manera en que, a través de la escritura, «uno va hacia el lenguaje en el lenguaje, y regresa a él a través del lenguaje, inmiscuido» (p. 78), transformado, en el marco formativo del empalabramiento que configura al ser humano y a lo que denomina «realidad», tal y como lo han planteado Duch y Chillón (2012), siguiendo la olvidada tradición del giro lingüístico inspirado en los planteamientos de Humboldt y Nietzsche; así como el estudio antropológico de las formas simbólicas deri- vadas de los presupuestos de Scheler y Cassirer.

En segundo lugar, la lectura que Larrosa (2013) hace del concepto de Bildung (formación) en cuanto invención, a partir del pensamiento de Nietzsche, concede unas pistas importantes al respecto. Este filósofo español suma a las vertientes filosóficas y pedagógicas expuestas en este artículo, el desarrollo de la Bildungsroman o novela de formación, en la que su personaje principal emprende un viaje que resulta ser hacia sí mismo, hacia su realización personal. Precisamente, la idea de formación que desarrolla Nietzsche se resume en la sentencia de Píndaro, «llegar a ser lo que se es», es decir, asumir la propia existencia como una obra en construcción que trasciende la realidad presente de la persona, lo cual, sin duda, se relaciona con ese desarrollo de la «ficción», pues supone una creación de lo no conocido, una invención desde mundos posibles.

Eso que somos y que tenemos que llegar a ser no es ya ni sujeto ni objeto, no es una "realidad" de ningún tipo, ni subjetiva ni objetiva, no es ni siquiera una "idea" que tendríamos que "realizar", sino que está claramente del lado de la invención. El hombre es un animal de invención, y las distintas formas de conciencia no son sino productos de esa función inventiva, de esa capacidad de invención [...] El "llegar a ser lo que se es" no está ya del lado de la lógica de la identidad, del autodescubrimiento, del autoconocimiento o de la autorrealización, sino del lado de la lógica desidentificadora de la invención (Larrosa, 2013, p. 127).

Esto se articula al tercer aspecto, relacionado con el sentido formativo de la ficción. Al respecto, diversos trabajos de Vargas Llosa $(1998,2002)$ han recalcado una evidente verdad que parece olvidarse en el acercamiento incauto a las obras literarias: la literatura es ficción, no la verdad fáctica que pretende la ciencia, aunque «la ficción es una mentira que encubre una profunda verdad» (1998, p. 13). Nabokov, en su célebre introducción a Curso de literatura europea, profundiza esta visión cuestionando el mismo sentido de «verdad» en el aparentemente verídico mundo natural, al cual compara con el literario.

La literatura es invención. La ficción es ficción. Calificar un relato de historia verídica es un insulto al arte y a la verdad. Todo gran escritor es un gran embaucador, como lo es la architramposa Naturaleza. La Naturaleza siempre nos engaña. Desde el engaño sencillo de la propagación 
de la luz a la ilusión prodigiosa y compleja de los colores protectores de las mariposas o de los pájaros, hay en la naturaleza todo un sistema maravilloso de engaños y sortilegios. El autor literario no hace más que seguir el ejemplo de la naturaleza. (Nabokov, 1980, p. 35)

Bien por rebeldía o simplemente por el cultivo de su arte, el hacedor de ficciones cuestiona el mundo establecido, lo que todos aceptan como realidad, proporcionando un mundo creado, nuevo, posible, pero cuyo producto es ficcional, no la «realidad real», objetiva. Esto no quiere decir que la literatura resulte un juego inocuo que no habla de la vida o de la realidad. «Todo lo contrario: por delirante que parezca, hunde sus raíces en la experiencia humana, de la que se nutre y a la que alimenta» (Vargas Llosa, 2002, p. 21), pues considera que el hombre no es solo producto de lo que le ha acontecido fácticamente, sino también de aquello que no sucedió, pero pudo haber sucedido o quiso que sucediese, por lo cual estas no-realizaciones las frustraciones, los deseos, los proyectos malogrados, las pasiones insatisfechas, los finales truncados- también hacen parte de lo que es, incluso a veces con más fuerza que lo que realmente acaeció, como lo planteó Ma- rías (1996) en un discurso de título diciente, Lo que no sucede y sucede.

En cuarto lugar, se insiste en que el lenguaje constituye la realidad humana, tal como lo evidencian diversos estudiosos de la formación como Heiddeger (2013), Vargas Guillén (2010) o Gadamer (2012), y una antropología de la comunicación como Un ser de mediaciones de Duch y Chillón (2012). En el planteamiento de esta formación literaria basada en la escritura de ficción, esto adquiere mayor trascendencia, pues la reconstrucción del lenguaje por medio de la acción poética conlleva el establecimiento de una realidad nueva. «La poesía revela este mundo; crea otro» (Paz, 2005, p. 13), constituyéndose en el «acto de creación en sí», por excelencia, pues implica el intento de construir ese lugar donde anida la existencia de los hombres, su mundo y su ser hecho de palabras: trazar un puente sobre esa distancia entre la palabra y la experiencia, unir lo que se dice con lo vivido. Esa búsqueda incesante y limitada para enunciar lo que el mundo y el hombre verdaderamente son; para vislumbrar la «esencia» del hombre desde su lenguaje.

Por supuesto, queda pendiente la discusión sobre hasta qué punto las producciones textua- les de estudiantes no poetas ni escritores pueden ser valoradas en este sentido creativo, en el marco de una sociedad que exacerba la «estetización del mundo» (Lipovetsky, 2015) y donde cualquier cosa puede ser considerada arte (Pardo, 2001). Esto conlleva las grandes preguntas de la teoría y la crítica literarias, ahora en los contextos educativos: ¿cómo definir allí lo literario, al no ser un concepto inmutable o absoluto (Aguiar e Silva, 2011; Warren y Wellek, 2009; Eagleton, 2002), cuyas contradicciones y paradojas pueden llevarlo incluso a su negación o relativización absoluta (Fussilo, 2012; Rancière, 2009; Arias y otros, 2013)? ¿Cómo valorar las obras de los estudiantes, si es que estas pueden considerarse como tales?

Por lo pronto, se ha fundamentado la formación (Bildung) como criterio esencial para contribuir a responder estos cuestionamientos, pues mediante el arte de la escritura y su realidad alternativa se da orden y sentido a esa existencia que fluye de manera inconmensurable y caótica, presentando un reflejo analizable -y quizá mejor experimentable- de lo que somos como especie, de lo que nos une como personas; esos universales que exploran nuestra condición humana desde nuestras singularidades: aquello que somos y que podríamos ser. 


\section{Referencias}

Aguiar e Silva, V. (2011). Teoría de la literatura. Madrid: Gredos.

Aristóteles. (2007). Arte poética/Arte retórica. México: Porrúa.

Aranguren, J. (2004). La idea de formación. Pensamiento y cultura, 7, 33-46.

Arias, R. et al.(2013). Qué hacemos con la literatura. Madrid: Akal.

Bajtín, M. (1992). Hacia una filosofía del acto ético. Barcelona: Antrophos.

Bárcena, F., \& Mèlich, J. (2014). La educación como acontecimiento ético. Natalidad, narración y hospitalidad. Buenos Aires: Miño y Dávila.

Bárcena, F. (2012). El alma del lector: la educación como gesto literario. Bogotá: Babel.

Béguin, A. (1997). Creación y destino I. México: Fondo de Cultura Económica.

Bolívar C., \& Gordo, A. (2016). Leer texto literario en la escuela: una experiencia literaria para encontrarse consigo mismo. La palabra, (29), 199-211.

Bombini, G. (1996). Didáctica de la literatura y teoría: apuntes sobre la historia de una deuda. Orbis Tertius, 1, 2-3.

Bruner, J. (2004). Realidad mental y mundos posibles. Los actos de la imaginación que dan sentido a la experiencia. Barcelona: Gedisa.

Bruner, J. (2000). La educación, puerta de la cultura. Madrid: Visor.

Cárdenas, A. (2004). Elementos para una pedagogía de la literatura. Bogotá: UPN.

Cárdenas, A. (2009). Literatura, pedagogía y formación en valores. Enunciación, 2(14), 5-20.

Colomer, T. (1995). La adquisición de la competencia literaria. En C. Lomas (Comp.), La educación literaria. Textos de Didáctica de la lengua y de la literatura (pp. 8-22). Barcelona: Graó.

Colomer, T. (1991). De la enseñanza de la literatura a la educación literaria. Comunicación, lenguaje y educación, 9, 21-31.

Cortázar, J. (2015). Rayuela. Bogotá: Alfaguara.

Delmiro Coto, B. (1995). El aprendizaje de la escritura literaria. En C. Lomas (Comp.), La educación literaria. Textos de Didáctica de la lengua y de la literatura (pp. 57-66). Barcelona: Graó. 
Duch L., \& Chillón, A. (2012). Un ser de mediaciones. Antropología de la comunicación (Vol. 1). Barcelona: Herder.

Eagleton, T. (2002). Una introducción a la teoría literaria. México: Fondo de Cultura Económica.

Eco, U. (1994). Introducción. En M. Serafini, Cómo se escribe (pp. 15-17). Barcelona: Paidós.

Espitia, T. (2013). Escribo para matar. La palabra, 23, 107-118.

Fabre, M. (2011). Experiencia y formación: la Bildung. Revista Educación y Pedagogía, 23(59), 215225.

Ferrer, E. (2002). Literatura y teoría literaria: el ser como construcción simbólica. Papeles,5, 13-18.

Fusillo, M. (2012). Estética de la literatura. Madrid: Antonio Machado.

Gadamer, H. G. (1975). Verdad y Método. Salamanca: Sígueme.

Garcés, J., \& Runge, A. (2011). Educabilidad, formación y antropología pedagógica: repensar la educabilidad a la luz de la tradición pedagógica alemana. Revista Científica Guillermo de Ockham, 9(2), 13-25.

Heidegger, M. (2013). Carta sobre el Humanismo. Madrid: Alianza.

Horlacher, R. (2014). ¿Qué es Bildung? El eterno atractivo de un concepto difuso en la teoría de la educación alemana. Pensamiento educativo. Revista de Investigación Educacional Latinoamericana, 1(51), 35-45.

Ipland, J. (1999). El concepto de Bildung en el neohumanismo alemán. Huelva: Hergué.

Jaeger, W. (2001). Paideia: los ideales de la cultura griega. México: FCE.

Kant, I. (2008). Sobre pedagogía. Córdoba: Encuentro.

Llovet, J., Caner Liese, R., Catelli Quiroga, N., \& Monterde, A. M. (2012). Teoría literaria y literatura comparada. Barcelona: Ariel.

Larrosa, J. (2013). La experiencia de la lectura. Estudios sobre literatura y formación. Barcelona: Laertes.

Lipovetsky, G. (2015). La estetización del mundo. Vivir en la época del capitalismo artístico. Barcelona: Anagrama. 
Marías, J. (1995). Lo que no sucede y sucede. El país. Recuperado el 20 de septiembre de 2015, de http://elpais.com/diario/1995/08/12/cultura/808178408_850215.html

Mélich, J. (2003). La sabiduría de lo incierto. Sobre ética y educación desde un punto de vista literario. Educar, 31, 33-45.

Meirieu, P. (2007). Frankenstein educador. Laertes: Barcelona.

Nabokov, V. (2010). Curso de literatura europea. Barcelona: RBA.

Nietzsche, F. (2002). La gaya ciencia. Madrid: Edaf.

Nussbaum, M. (1995). Poetic justice. The literary imagination and public life. Boston: Beacon press.

Nussbaum, M. (2012). El cultivo de la humanidad. Una defensa clásica de la reforma en la educación liberal. Barcelona: Paidós.

Pardo, J. (2001). A cualquier cosa llaman arte. Ensayo sobre la falta de lugares. En: J. Larrosa y C. Skliar (eds.), Habitantes de Babel. Poéticas y políticas de la diferencia (pp. 317-341). Barcelona: Laertes.

Paz, O. (2005). El arco y la lira. El poema, la revelación poética. Poesía e historia. México: Fondo de Cultura Económica.

Quintana, J. M. (1986). El concepto de Bildung en el pensamiento alemán. Roma: Ediz.

Rancière, J. (2009). La palabra muda. Ensayos sobre las contradicciones de la literatura. Madrid: Eterna cadencia.

Reyzábal, M., \& Tenorio, P. (1994). El aprendizaje significativo de la literatura. Madrid: La Muralla.

Ricoeur, P. (1995). Tiempo y narración. México: Siglo XXI.

Rivera-Garza, C. (2010). La escritura solamente. En M. Bellatín (coord.), El arte de enseñar a escribir (pp. 78-82). México: FCE.

Rosenblatt, L. (2002). La literatura como exploración. México: Fondo de Cultura Económica.

Saavedra, S. (2011). La creación literaria en el ámbito educativo: de la estructura superficial a la construcción narrativa de la realidad. Lenguaje, 39, 395-417.

Saavedra, S. (2013). Hacia una evaluación formativa, crítica y artística de la creación literaria. Folios, $37,167-183$. 
Sábato, E. (2014). El escritor y sus fantasmas. Barcelona: Seix Barral.

Todorov, T. (2009). La literatura en peligro. Barcelona: Círculo de lectores-Galaxia Gutenberg.

Vargas Guillén, G., Gamboa Sarmiento, S., \& Paul Reeder, H. (2010). La humanización como formación. La filosofía y la enseñanza de la filosofía en la condición postmoderna. Bogotá: San Pablo.

Vargas Llosa M. (1998). Cartas a un joven novelista. Bogotá: Planeta.

Vargas Llosa, M. (2002). La verdad de las mentiras. Madrid: Santillana.

Vilanou, C. (2001). De la Paideia a la Bildung; hacia una pedagogía hermenéutica. Revista Portuguesa de Educaçao, 2(14), 3-30.

Warren, A., \& Wellek, R. (2009). Teoría literaria. Madrid: Gredos. 